\title{
PROCESS OF ORLISTAT-LOADED CHITOSAN NANOPARTICLES USING BOX-BEHNKEN DESIGN - AN EVALUATION STUDY
}

\begin{abstract}
SRINIVAS MURTHY BR ${ }^{1 *}$, PRASANNA RAJU YELAVARTHI ${ }^{2}$, DEVANNA N ${ }^{3}$
${ }^{1}$ Research Scholar, Department of Pharmaceutical Sciences, Jawaharlal Nehru Technological University Anantapur, Anantapuramu, Andhra Pradesh, India. 'Department of Pharmaceutics Division, Sri Padmavathi School of Pharmacy, Tiruchanoor, Tirupati, Andhra Pradesh, India. ${ }^{3}$ Department of Chemistry and Director, Oil Technological and Pharmaceutical Research Institute, Jawaharlal Nehru Technological University Anantapur, Anantapuramu, Andhra Pradesh, India. Email: seenu46@gmail.com
\end{abstract}

Received: 25 February 2021, Revised and Accepted: 01 April 2021

\section{ABSTRACT}

Objective: High lipophilicity and extensive hepatic metabolism limit oral application of orlistat in obesity treatment. Orlistat-loaded chitosan nanoparticles (CONPs) were optimized by 3-factor 3-level Box-Behnken design (BBD) and surfaced engineered to address limitations.

Methods: CONPs were prepared by ionic gelation method. Amounts of chitosan $\left(\mathrm{X}_{1}\right)$, sodium tripoly phosphate $\left(\mathrm{X}_{2}\right)$, and orlistat $\left(\mathrm{X}_{3}\right)$ were selected as independent factors, whereas \% entrapment efficiency $\left(\mathrm{Y}_{1}\right)$ and \% drug release $\left(\mathrm{Y}_{2}\right)$ were employed as responses in BBD. Three-dimensional response surface plots were run to understand the main interaction and quadratic effects of independent variables. Further optimized formulation was surface engineered by Eudragit L-100 (ECONPs) and characterized by FTIR, DSC, XRD, particle size, zeta potential, and SEM. Entrapment efficiency, release kinetics, stability, and in vitro cell line studies were carried out

Results: ECONPs were produced with an average size of $534.6 \mathrm{~nm}$, zeta potential of $+5.7 \mathrm{mV}$, EE of $78.62 \%$, and DR of $80.86 \%$. Eudragit coated CONPs anchored the release of orlistat at pH 6.8 desirable for duodenal targeting. Orlistat was released with low, burst, and sustained release manner over $24 \mathrm{~h}$ period followed first-order kinetics with Higuchi model with drug content of $84.87 \%$ and $78.44 \%$ of release. ECONPs possessed lipase inhibition with $\mathrm{IC}_{50}$ value of $8.0 \mu \mathrm{g} / \mathrm{ml}$ and viability against selected cell lines with $\mathrm{CTC}_{50}$ values $(26.32-32.21 \mu \mathrm{g} / \mathrm{ml})$.

Conclusion: BBD was a promising tool in elucidating the insights of formulation variables of CONPs. ECONPs fulfilled the rationale of orlistat release, lipase inhibition, and viability against selected cell lines.

Keywords: Chitosan, Hyperlipidemia, Ionic gelation, Orlistat, Response surface method.

(C) 2021 The Authors. Published by Innovare Academic Sciences Pvt Ltd. This is an open access article under the CC BY license (http://creativecommons.org/ licenses/by/4.0/) DOI: http://dx.doi.org/10.22159/ajpcr.2021v14i5.41441. Journal homepage: https://innovareacademics.in/journals/index.php/ajpcr

\section{INTRODUCTION}

The World Health Organization (WHO) pronounces that the obesity is as a chronic metabolic disease which affects $13 \%$ of world's population and its prevalence was tripled between 1975 and 2016 [1]. Obesity leads to cardiovascular disorders, osteoarthritis, disability and death $[2,3]$. Statins, fibrates, lipase inhibitors, bile acid sequesterants, and nicotinic acid derivatives are currently employed for the treatment of hyperlipidemia and obesity [4], but their therapeutic effectiveness is limited due to unavailability of targeted formulations.

Orlistat (tetrahydrolipstatin) is a lipase inhibitor and has poor water solubility, low melting point, low chemical stability, extensive first pass metabolism, waxy nature, and poor bioavailability $(<10 \%)$ [5-7]. Orlistat was explored by various techniques such as extrusion, spheronization, micronization, pelletization, nanoemulsions, and multi-unit pellet systems (MUPS) [8]. However, none of the above approaches have effective against site specific release. Hence, orlistat requires effective formulation technology for specific/targeted delivery [9].

Chitosan, a biopolymer made nanoparticles were proved to be promised to circumvent such formulation based limitations $[10,11]$. Ionic gelation method was reliable to produce polymeric nanoparticles. Box-Behnken experimental design (BBD) is a successful statistical tool in design and optimization of the drug-loaded polymeric NPs [12,13]. Surface engineering of NPs was practiced to achieve site specific/ targeted release of many therapeutic moieties [14].
With above context, orlistat-loaded nanoparticles were designed and optimized by employing BBD, coated with Eudragit L-100 and assessed for their formulation effectiveness.

\section{METHODS}

Orlistat was a generous gift of M/s Aurobindo Pharma Ltd (Hyderabad, India), Chitosan, (water soluble, MW 50-100 kDa and degree of deacetylation $>85 \%$ ) was purchased from Aura Biotechnologies Pvt. Ltd, (Chennai, India). Sodium tripolyphosphate (TPP) was purchased from Sigma-Aldrich (Bangalore, India). Eudragit L-100, lactose was obtained from SD Fine Chem (Chennai, India). Porcine pancreatic lipase (Type II, EC 3.1.1.3), sodium deoxycholate, sodium phosphate monobasic, isopropanol, and p-nitrophenyl palmitate (pNPP), p-nitrophenyl butyrate (pNPB) purchased from M/s. Sigma-Aldrich (Bengaluru, India). Milli Q water was used throughout the study. All other chemicals and materials used in the study were generally recognized as safe with the pharmaceutical grade.

\section{Drug-excipient compatibility studies (FTIR)}

The identification of drug, its compatibility with excipients (chitosan, TPP) and their physical mixture were studied by Fourier Transform Infrared (FTIR) Spectroscopy (Shimadzu 8300E). FTIR spectra of orlistat, chitosan, TPP and their physical mixture were studied by $\mathrm{KBr}$ pellet method. Each spectrum of the sample was collected from 32 single average scans at a resolution of $4 \mathrm{~cm}^{-1}$ in the absorption region of $400-4000 \mathrm{~cm}^{-1}$ [15].

Preparation of orlistat-encapsulated chitosan nanoparticles Orlistat-loaded chitosan nanoparticles (CONPs) were developed by ionic gelation of chitosan with TPP as cross linking agent. Various concentrations 
of polymeric solution were prepared by dissolving chitosan in Milli-Q water. The $\mathrm{pH}$ of the polymeric solution was adjusted to $4.7-4.8$ with $0.5 \%$ aqueous sodium hydroxide and equilibrated at $35 \pm 2^{\circ} \mathrm{C}$. The polymeric solution was filtered to remove undissolved or remnant chitosan particles through a syringe filter ( $0.45 \mu \mathrm{m}$, Millipore, Billerica, MA). Later, specified quantity of orlistat (dissolved in $0.5 \mathrm{ml}$ of methanol) was added to the polymeric solution. Prescribed quantity of cross linker, TPP dissolved in Milli-Q water was passed through a syringe filter (pore size $0.22 \mu \mathrm{m}$,) and added drop-wise to the polymeric solution at preset constant stirring rate of 1000rpm. The resultant nanodispersion was sonicated further for $20 \mathrm{~min}$. Subsequently, all other batches of nanopreparations were centrifuged at 10,000 rpm for $30 \mathrm{~min}$; the sediment formed was dispersed in $1 \%$ lactose as cryoprotectant, lyophilized at $-80^{\circ} \mathrm{C}$ for $24 \mathrm{~h}$ and stored for further studies [10]. A total of 17 formulations were prepared at varied levels of factors as shown in Table 1.

\section{Box-Behnken experimental design}

Response surface methodology was adapted to optimize chitosan nanoparticles and correlate responses and factors. The study was focused to maximize encapsulation efficiency and cumulative drug release. BoxBehnken design was employed to evaluate the main interaction, and quadratic effects of chitosan concentration, TPP concentration and dose of orlistat on encapsulation and cumulative drug release. The three-factor three-level design was employed to get the second-order polynomial models using Stat-Ease's Design-Expert- $8^{\circledR}$ (Version 8.0.7.1, Minneapolis, MN, USA). A design comprising 17 runs was developed, for which, the nonlinear computer-generated quadratic model can be expresses as:

$R=b_{0}+b_{1} A+b_{2} B+b_{3} C+b_{12} A B+b_{13} A C+b_{23} B C+b_{11} A^{2}+b_{22} B^{2}+b_{33} C^{2}(1)$

Where, $\mathrm{R}$ is response, $\mathrm{b}_{0}$ is intercept, $\mathrm{b}_{1}$ to $\mathrm{b}_{33}$ are regression coefficients computed from the observed values of $\mathrm{R}$ from experiments, and $\mathrm{A}, \mathrm{B}$, and $C$ are independent variables. The terms $(A B, A C$, and $B C)$ and $\left(A^{2}\right.$, $B^{2}$, and $C^{2}$ ) represent the interaction and quadratic terms, respectively. Chitosan concentration (A), TPP concentration (B), and orlistat dose (C) are selected as independent variables. Their concentration ranges are depicted in Table 2 with low, medium, and high levels, which were selected on the basis of preliminary experiments in developing the nanoparticles. Encapsulation efficiency $\left(Y_{1}\right)$ and cumulative drug release $\left(\mathrm{Y}_{2}\right)$ were taken as dependent variables [16-18].

Optimization, data analysis, and validation of the applied model ANOVA was used for the statistical validation of the polynomial equations generated by Design- Expert ${ }^{\circledast}$. All the responses were fitted

Table 1: BBD matrix with three independent variables at three levels and observed responses

\begin{tabular}{|c|c|c|c|c|c|}
\hline \multirow[t]{2}{*}{ Run } & Factor 1 & Factor 2 & Factor 3 & $\begin{array}{c}\text { Response } 1 \\
\left(Y_{1}\right)\end{array}$ & $\begin{array}{c}\text { Response } 2 \\
\left(\mathrm{Y}_{2}\right)\end{array}$ \\
\hline & $\begin{array}{c}\text { A:Chitosan } \\
\text { (mg) }\end{array}$ & $\begin{array}{c}\text { B:TPP } \\
\text { (mg) }\end{array}$ & $\begin{array}{c}\text { C:Orlistat } \\
\text { (mg) }\end{array}$ & EE (\%) & DR (\%) \\
\hline 1 & 1000 & 400 & 60 & $41.68 \pm 0.69$ & $63.87 \pm 0.81$ \\
\hline 2 & 1000 & 600 & 90 & $81.62 \pm 0.1 .13$ & $83.64 \pm 0.82$ \\
\hline 3 & 500 & 800 & 90 & $59.24 \pm 0.49$ & $68.13 \pm 0.28$ \\
\hline 4 & 1000 & 600 & 90 & $82.09 \pm 0.29$ & $85.67 \pm 1.17$ \\
\hline 5 & 500 & 400 & 90 & $73.84 \pm 0.36$ & $69.82 \pm 0.57$ \\
\hline 6 & 1500 & 800 & 90 & $97.15 \pm 0.57$ & $97.52 \pm 0.89$ \\
\hline 7 & 1000 & 800 & 120 & $66.57 \pm 0.91$ & $81.53 \pm 1.18$ \\
\hline 8 & 1000 & 600 & 90 & $82.59 \pm 0.66$ & $87.24 \pm 0.71$ \\
\hline 9 & 500 & 600 & 60 & $64.58 \pm 1.38$ & $62.37 \pm 0.48$ \\
\hline 10 & 1000 & 400 & 120 & $76.93 \pm 0.89$ & $84.19 \pm 0.56$ \\
\hline 11 & 500 & 600 & 120 & $72.56 \pm 1.37$ & $69.76 \pm 1.07$ \\
\hline 12 & 1000 & 600 & 90 & $83.05 \pm 0.41$ & $88.08 \pm 1.00$ \\
\hline 13 & 1000 & 600 & 90 & $84.86 \pm 0.47$ & $88.37 \pm 0.25$ \\
\hline 14 & 1500 & 600 & 120 & $97.83 \pm 0.93$ & $93.21 \pm 0.28$ \\
\hline 15 & 1500 & 400 & 90 & $65.26 \pm 0.73$ & $80.14 \pm 1.02$ \\
\hline 16 & 1000 & 800 & 60 & $61.92 \pm 0.05$ & $83.15 \pm 0.34$ \\
\hline 17 & 1500 & 600 & 60 & $65.28 \pm 0.33$ & $80.24 \pm 0.79$ \\
\hline
\end{tabular}

to linear, second order, and quadratic models and then evaluated in terms of statistical significance of coefficients and $\mathrm{R}^{2}$ squared values. Different possibilities were tried to find out the constituents for the optimized nanoparticles.

The three-dimensional (3D) response surface graphs were envisaged to draw relationship and interaction between the coded variables and the response. The optimum concentrations of independent variables based on the responses constrained in their minimum levels were selected. Total seven formulations were selected by point prediction; the checkpoint (optimized) formulations were formulated and characterized for the selected responses. The observed response values were compared with the predicted values and prediction errors (\%) were calculated. The linear correlation and residual plots between observed and predicted responses were obtained $[19,20]$.

\section{Entrapment efficiency (\%EE)}

The amount of orlistat entrapped in NPs was determined by an indirect method. Before lyophilization, the suspension was centrifuged at $10,000 \mathrm{rpm}$ for 15 min using centrifuge (REMI Centrifuge, Mumbai, India). The supernatant was separated, filtered, and quantified by UV spectrophotometer at $205 \mathrm{~nm}$ [21]. The EE was calculated from following equation.

$$
\mathrm{EE}(\%)=\frac{\mathrm{W}_{\mathrm{t}}-\mathrm{W}_{\mathrm{s}}}{\mathrm{W}_{\mathrm{t}}} \times 100
$$

Where, $W_{t}$ represents the total amount of orlistat used for the preparation of nanoparticles and $W_{s}$ represents the amount of unencapsulated orlistat present in the supernatant.

\section{In vitro drug release study}

The release of orlistat from CONPs was determined using dialysis tube. Nanoparticles equivalent to $50 \mathrm{mg}$ orlistat (dispersed in $10 \mathrm{ml}$ of medium) were loaded in a dialysis cassettes (MW 12,000-14,000 g/mol, pore size of $2.4 \mathrm{~nm}$ ). The bags were suspended in dissolution vessels containing $500 \mathrm{ml}$ of phosphate buffer $\left(\mathrm{pH} \mathrm{7.4)}\right.$ at $37^{\circ} \mathrm{C} \pm 0.5^{\circ} \mathrm{C}$ with a paddle rotation speed at $80 \mathrm{rpm}$ (USP Type-II). Aliquot of $5 \mathrm{ml}$ samples was withdrawn at predetermined intervals by maintaining the sink condition. Further, the samples were filtered through a $0.22 \mu \mathrm{m}$ membrane filter disk and analyzed. The experiment was repeated for six independent observations. To study the possible release mechanisms of orlistat, the drug release data were fitted to various kinetic models such as zero-order, first-order, Higuchi, Hixson Crowell, and the KorsmeyerPeppas models [22]

\section{Identification of optimized formulation}

Based on the entrapment efficiency and drug release data of 17 formulations, numerical optimization technique was adapted for optimizing the formulation variables to obtain desired responses. Further experiments were repeated in triplicate to determine the dependability of optimized conditions. Mean values of experimental data were compared against predicted values and thus percent error was determined.

Table 2: Levels of independent and dependent variables used in BBD

\begin{tabular}{|c|c|c|c|}
\hline \multirow[t]{2}{*}{ Factor } & \multicolumn{3}{|c|}{ Levels used, actual (coded) } \\
\hline & Low $(-1)$ & Medium (0) & High $(+1)$ \\
\hline \multicolumn{4}{|l|}{ Independent variables } \\
\hline $\mathrm{A}=$ Chitosan conc. $(\% \mathrm{w} / \mathrm{v})$ & 0.5 & 1 & 1.5 \\
\hline $\mathrm{B}=$ Sod. TPP $(\% \mathrm{w} / \mathrm{v})$ & 0.4 & 0.6 & 0.8 \\
\hline $\mathrm{C}=$ Orlistat $(\mathrm{mg})$ & 60 & 90 & 120 \\
\hline \multicolumn{4}{|l|}{ Dependent variables } \\
\hline $\mathrm{Y}_{1}=\%$ Entrapment & & Maximize & \\
\hline Efficiency (\%EE) & & Maximize & \\
\hline $\mathrm{Y}_{2}=\%$ Drug Release ( $\left.\% \mathrm{DR}\right)$ & & & \\
\hline
\end{tabular}


Surface engineering of optimized formulation

Preparation of Eudragit L 100 coated CONPs (ECONPS)

As per Tayel et al. (2015) method, the optimized nanoparticles were sonicated ( $5 \mathrm{~min}$ ) in $50 \mathrm{ml}$ phosphate buffer ( $\mathrm{pH}$ 6.8) to which Eudragit L100 $(0.5 \% \mathrm{w} / \mathrm{v})$ was previously dissolved. The resulting dispersion was centrifuged at 10,000 rpm for $15 \mathrm{~min}$; the sediment obtained was frozen, lyophilized using lactose $(1 \% \mathrm{w} / \mathrm{v})$ as cryoprotectant. Thus, obtained ECONPs were characterized $[14,23]$.

\section{Characterization of optimized ECONPs}

Particle size, zeta potential, and Poly dispersity index (PDI)

The particle size, zeta potential, and PDI of ECONPs were measured by dynamic light scattering (DLS) using a Zetasizer (Horiba SZ-100). DLS measurements were performed at $25 \pm 0.5^{\circ} \mathrm{C}$ with a scattering angle of $90^{\circ}[24]$.

\section{Surface morphology}

The surface morphology of ECONPs was characterized using scanning electron microscope operating at $15 \mathrm{kV}$ (Quanta FEG 200). NPs placed in the electron microscope were non-destructively bombarded by a finely focused beam (probe) of electrons. The secondary electrons produced by the NPs were used to characterize particle morphology. Dried ECONPs were adhered on to the aluminum stubs using double sided adhesive tape and the stubs were sputter coated with gold for $300 \mathrm{~S}$ at $15 \mathrm{Ma}$. The samples were then randomly scanned and photomicrographs were taken with SEM [25].

\section{X-ray diffraction studies}

X-ray diffraction (XRD) experiments were performed using X-ray diffractometer (Horizon,) using $\mathrm{Cu}$ K2 $\alpha$ rays $(\lambda=1.54056 \AA)$ with a voltage of $25 \mathrm{kV}$ and a current of $30 \mathrm{~mA}$, in flat plate $\theta / 2 \theta$ geometry, over the $2 \theta$ ranges $25-70^{\circ}$, with a step width $0.05^{\circ}$ and a scan time of $2.0 \mathrm{~s}$ per step. Diffraction patterns for orlistat, chitosan, and drug loaded nanoparticles were analyzed [26].

\section{Differential scanning calorimetry}

Differential scanning calorimetric analysis was used to characterize the thermal behavior using differential scanning calorimetry (DSC-60, Shimadzu). About $2.0 \mathrm{mg}$ of dried ECONPs was crimped in a standard aluminum pan and heated from $20^{\circ} \mathrm{C}$ to $350^{\circ} \mathrm{C}$ at a heating rate of $10^{\circ} \mathrm{C}$ / min under constant purging of nitrogen ( $40 \mathrm{ml} / \mathrm{min})$ [27].

\section{In vitro drug release study of ECONPs}

In dialysis tubing, ECONPs equivalent to $50 \mathrm{mg}$ of orlistat was loaded with $10 \mathrm{ml}$ medium. The study was conducted in $0.1 \mathrm{~N} \mathrm{HCl} \mathrm{(pH} \mathrm{1.2,} 2 \mathrm{~h}$ ) and then in phosphate buffer ( $\mathrm{pH}$ 6.8). Release of drug from ECONP's in the initial $2 \mathrm{~h}$ and later was analyzed [28].

\section{Stability studies}

The stability of ECONPs was examined as per the International Council of Harmonization ( ICH) guidelines, Q1A (R2). The optimized freeze dried ECONPs were kept in sealed glass vials $(n=3)$ and were stored at $25 \pm 2{ }^{\circ} \mathrm{C}$ with a relative humidity (RH) of $60 \pm 5 \%$ for 3 months in stability chamber (Remi, Mumbai, India). Samples were collected at a monthly interval and evaluated for morphology, zeta potential, FTIR, drug content, and DR [29].

\section{Lipase inhibition}

Since the majority of triglyceride hydrolysis is done by pancreatic lipase, porcine pancreatic lipase was used as a model enzyme. Crude lipase was dissolved in reaction buffer $(10 \mathrm{mg} / \mathrm{ml})$ and centrifuged at $7000 \mathrm{rpm}$ for $10 \mathrm{~min}$ to remove insoluble substances. About $1 \mathrm{mg} / \mathrm{ml}$ stock solution in 1\% DMSO was prepared, from which five different solutions were prepared with the following concentrations: $50,100,200,300$, and $400 \mu \mathrm{g} / \mathrm{ml}$. All the solutions were prepared freshly before the study. A stock solution of pNPB (p-nitrophenyl butyrate) was prepared by dissolving $20.9 \mathrm{mg}$ of $\mathrm{PNPB}$ in $2 \mathrm{ml}$ of acetonitrile.
In vitro assay for determination of lipase inhibition

Lipase assay were performed in a 96-well, clear, flat bottomed plate with $200 \mu \mathrm{l}$ reaction volume. pNPP was used as a substrate with a reaction buffer of $50 \mathrm{mM}$ sodium phosphate, $5 \mathrm{mM}$ sodium deoxycholate, and $10 \%$ isopropanol at $\mathrm{pH}$ 8.0. $200 \mu \mathrm{l}$ reaction volumes were used and substrate conversion was monitored at $410 \mathrm{~nm}$. All assays were run at $37^{\circ} \mathrm{C}$ and reported results are average of three replicates [9].

\section{In vitro cell line study (MTT assay)}

\section{Cell lines and culture conditions}

The cell permeability studies of test samples were carried out against various cell lines as per the standard protocols. Mouse fibroblast 3T3-L1 preadipocytes, NSC-34 (Mice motor neuron like), and Kidney epithelial cells (Vero cells) used in the study were procured from National Centre for Cell Science (NCCS), Pune, India. Cells were cultured in Dulbecco's modified Eagle's medium (DMEM) supplemented with 10\% $(v / v)$ fetal bovine serum (FBS), $1 \%$ antibiotic/antimycotic solution and the cells were routinely sub-cultured and propagated in a humidified $\mathrm{CO}_{2}$ incubator at $5 \% \mathrm{CO}_{2}, 37^{\circ} \mathrm{C}$, and $95 \%$ humidity.

\section{Sample preparation}

Stock solution $(1 \mathrm{mg} / \mathrm{ml})$ of the test sample was prepared in dimethyl sulfoxide (DMSO, $1 \% \mathrm{v} / \mathrm{v}$ ). The working solutions were prepared by serially diluting the stock solutions with the culture medium. Finally, the working solution sets were filtered using $0.22 \mu \mathrm{m}$ sterile syringe filters (Millipore, India) before use.

\section{Method}

The cell cultures were trypsinized and the cell count was adjusted to $1.0 \times 10^{5}$ cells $/ \mathrm{ml}$ using a medium containing $10 \%$ new born calf serum. The diluted cell suspension $(0.1 \mathrm{ml})$ was inoculated to $96-$ well microplates and incubated for $24 \mathrm{~h}$ and allowed to adhere. About $100 \mu \mathrm{l}$ of test samples (ECONPs) and pure orlistat were added to each well. The plates were then incubated at $37^{\circ} \mathrm{C}$ in $5 \% \mathrm{CO}_{2}$ atmosphere for $72 \mathrm{~h}$ incubation, and then aspirated. About $10 \mu \mathrm{l}$ Tetrazolium salt (MTT) solution was added to each well and further incubated for $4 \mathrm{~h}$ at $37^{\circ} \mathrm{C}$. After incubation, $100 \mu \mathrm{l}$ of DMSO was added to each well and after $15 \mathrm{~min}$ the absorbance was measured at $540 \mathrm{~nm}$ using microplate reader [30-31].

$$
\% \text { Viability }=\frac{\text { Absorbance of the test sample }}{\text { Absorbance of the control }} \times 100
$$

\section{RESULTS}

The Box-Behnken design matrix with independent and dependent variables along with their experimental levels is demonstrated in Table 2 and their responses are illustrated in Table 1. The independent variables measured for different batches showed wide variation ranging from 41.68 to $97.83 \%$ for EE and from 62.37 to $97.52 \%$ for DR. Obtained values clearly indicated the EE and DR of CONPs were influenced by selected variables. The following second-order polynomial equations in coded form were established to draw the relationship between dependent and independent variables upon multiple regression analysis.

$Y_{1}=82.84+6.91 \mathrm{~A}+3.40 \mathrm{~B}+10.05 \mathrm{C}+2.16 \mathrm{~A}^{2}-11.13 \mathrm{~B}^{2}-9.94 \mathrm{C}^{2}+11.62 \mathrm{AB}+6.14 \mathrm{AC}-$ $7.65 \mathrm{BC}$

$\mathrm{Y}_{2}=86.60+10.13 \mathrm{~A}+4.04 \mathrm{~B}+4.88 \mathrm{C}-4.74 \mathrm{~A}^{2}-2.95 \mathrm{~B}^{2}-5.46 \mathrm{C}^{2}+4.77 \mathrm{AB}+1.39 \mathrm{AC}-$ $5.49 \mathrm{BC}$

Where, $\mathrm{Y}_{1}$ and $\mathrm{Y}_{2}$ are EE and DR of ECONPs. A, B, and C are amounts of chitosan, TPP and orlistat, respectively. Interaction terms $(\mathrm{AB}, \mathrm{AC}$, and $\mathrm{BC}$ ) were evident with change of responses while two variables changed simultaneously, while the effect of changes in each single variable on the response was reflected by the main effect terms (A, B, and $\mathrm{C}$ ) and quadratic terms $\left(\mathrm{A}^{2}, \mathrm{~B}^{2}\right.$, and $\left.\mathrm{C}^{2}\right)$. 
The parity plots (Fig. 1) demonstrated the correlation between model predictions and observed responses. High correlation coefficient values $\left(\mathrm{R}_{1}=0.9556\right.$ for $\mathrm{EE}$ and $\mathrm{R}_{2}=0.9781$ for $\left.\mathrm{DR}\right)$ demonstrated good correlation between observed responses and responses predicted by the quadratic models. Normal (percentage) probability plots of the residuals (Fig. 1) demonstrated that errors were normally distributed, independent of each other with homogenous error variance. Residual plots of Fig. 1 showed random distribution of residuals without any trend, indicated good prediction of maximum response along with constant variance. These data further confirm the reliability of quadratic models.

Interactive effects of independent variables on the responses were demonstrated by 3D response surface graphs and two-dimensional contour plots (Figs. 2-3). The plot was function of two factors, while maintaining all other factors at fixed levels. The graphs (Figs. 2 and 3) were derived from equations ( 4 and 5 ) by keeping one variable constant at its central level for each plot, while varying the levels of other two variables within the experimental range. Fig. 2 illustrated the response surface plots and their corresponding contour plots with a slight increase in EE (73.84-74.41\%) with increased chitosan concentration. An initial increase (73.48-79.54\%) and subsequent decrease (59.24\%) in EE was observed with increase in TPP concentration, whereas linear increase in EE was observed with increased orlistat dose (54.36$77.59 \%$ ) based on equation (4).

The response surface and contour plots of DR were (Fig. 3) based on Equation (5). As evident from the graphs, an increase in chitosan concentration increased the DR (69.82-80.14\%) and increase in TPP concentration had a dual effect, that is, slight increase (72.19\%), followed by decrease $(68.76 \%)$, whereas orlistat dose had a positive effect on DR (55.35-73.23\%). The drug release from CONPs is depicted in Figs. 4 and 5.

The optimum conditions to fabricate ECONPs were obtained by solving equations ( 4 and 5 ) for different values of independent variables within the experimental range, followed by desirability calculation. Optimum condition case was when conditions yielding nanoparticles with high $\mathrm{EE}$ and DR (more than 60\%). Composite desirability of the system at different conditions within the experimental range was calculated, and the conditions at which the composite desirability of system at $0.90-1$ were selected as the optimal conditions.

\section{Identification of optimized formulation}

EE and DR were selected as responses for optimization of nanoparticles. EE was ranged between 41.68 and $97.83 \%$ whereas DR was between 62.37 and $97.52 \%$ for CONPs. Based on the numerical optimization technique, the optimum conditions for production of CONP's with maximum EE and DR in the experimental area in this study were found to be chitosan concentration (900 mg), TPP concentration (696.81 $\mathrm{mg}$ ), and optimum dose of orlistat $(95 \mathrm{mg})$. At these conditions, nanoparticles with EE of $80.03 \%$ and DR of $85.35 \%$ were obtained and confirmed by check point analysis which was repeated in triplicate to determine the dependability of optimized conditions. The observed responses $(78.62 \%$ for EE and $83.14 \%$ for DR) for the optimized formulation were close to the predicted values $(80.03 \%$ for EE and $85.35 \%$ for DR) with percent error of $1.76 \%$ for EE and $2.58 \%$ for DR with a desirability of 0.903 demonstrated the accuracy of predicted optimum conditions.

\section{Characterization of optimized nanoparticles}

Particle size and zeta potential

The average particle size of the optimized ECONPs was found to be $534.6 \mathrm{~nm}$, electro kinetic potential was $+5.7 \mathrm{mV}$ with PDI was $<1$ indicated the formation of stable nanoparticles.

\section{Surface morphology-SEM}

Optimized ECONPs (Fig. 6) were found to be discrete, regular, spherical to oval shaped, and loose aggregates with rough texture due to uneven spreading of coating solution.
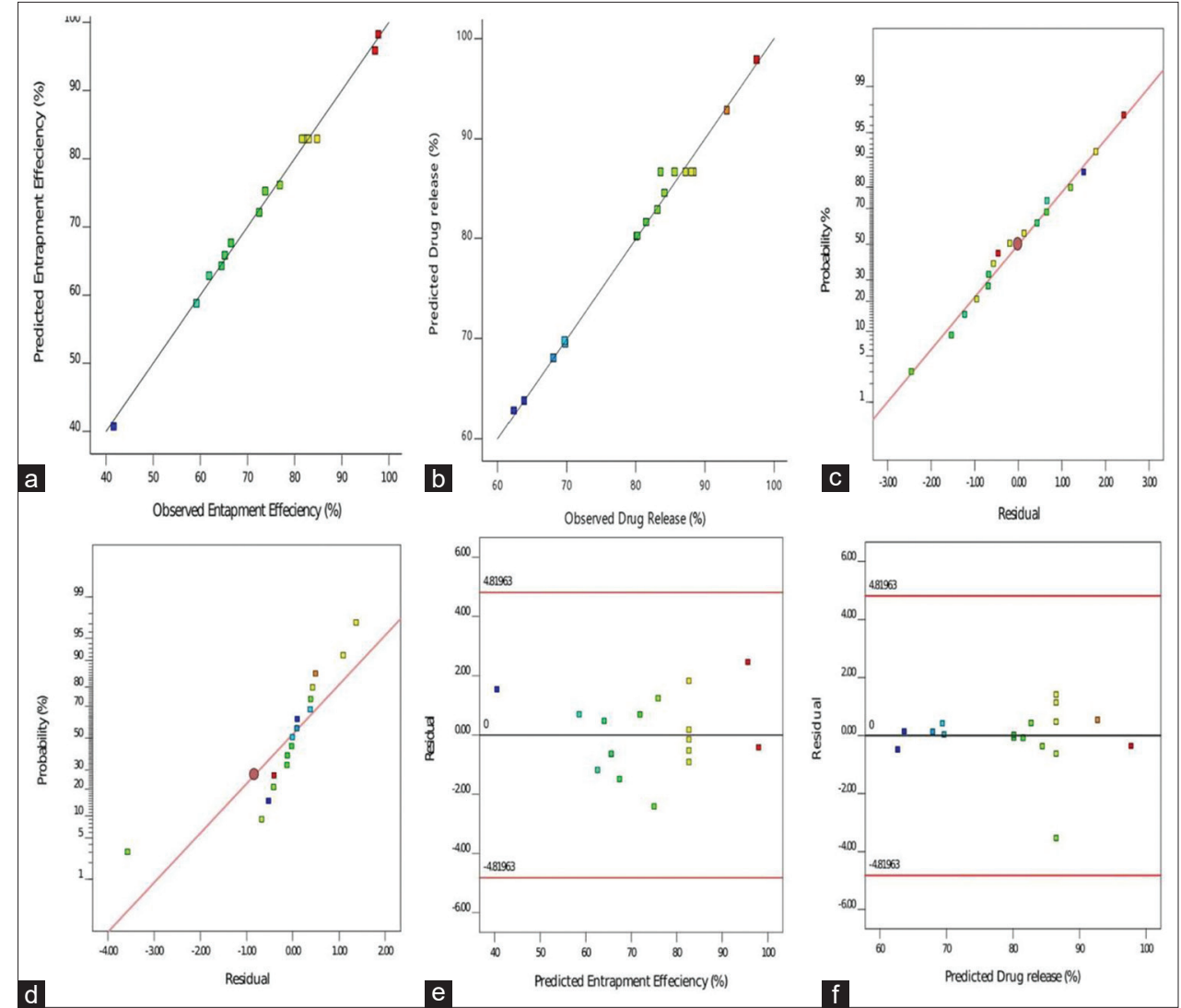

Fig. 1: Parity charts of predicted versus observed responses for (a) entrapment efficiency and (b) drug release. Normal (percentage) probability of residuals for (c) entrapment efficiency and (d) drug release. Residual plot of (e) entrapment efficiency and (f) drug release 

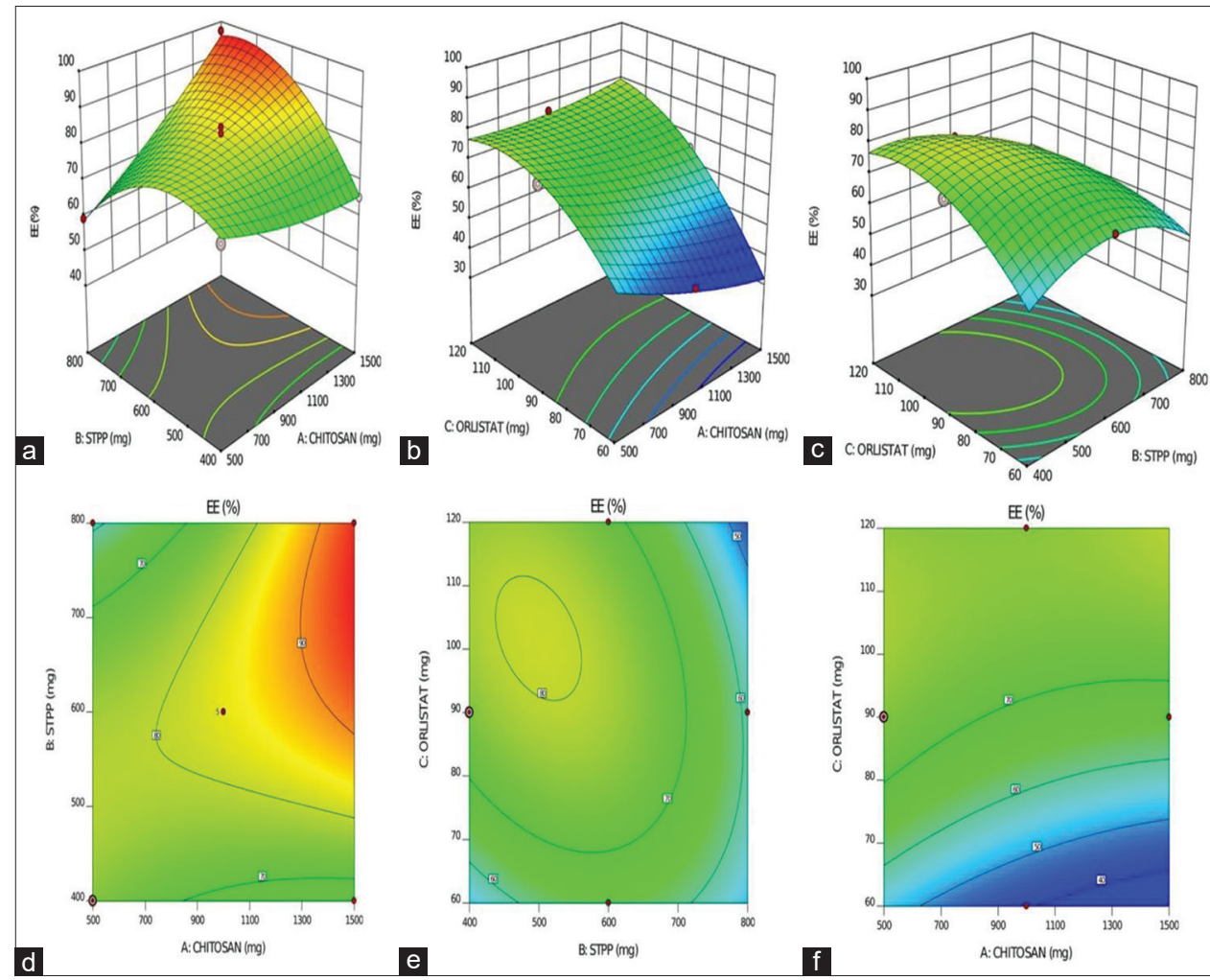

Fig. 2: Three-dimensional response surface plots showing the effect of variables on entrapment efficiency, (a) effect of chitosan and TPP, (b) effect of chitosan and orlistat (c) effect of TPP and orlistat. Contour plots showing effects of variables on EE. (d) Effect of chitosan and TPP, (e) effect of chitosan and orlistat, (f) effect of TPP and orlistat
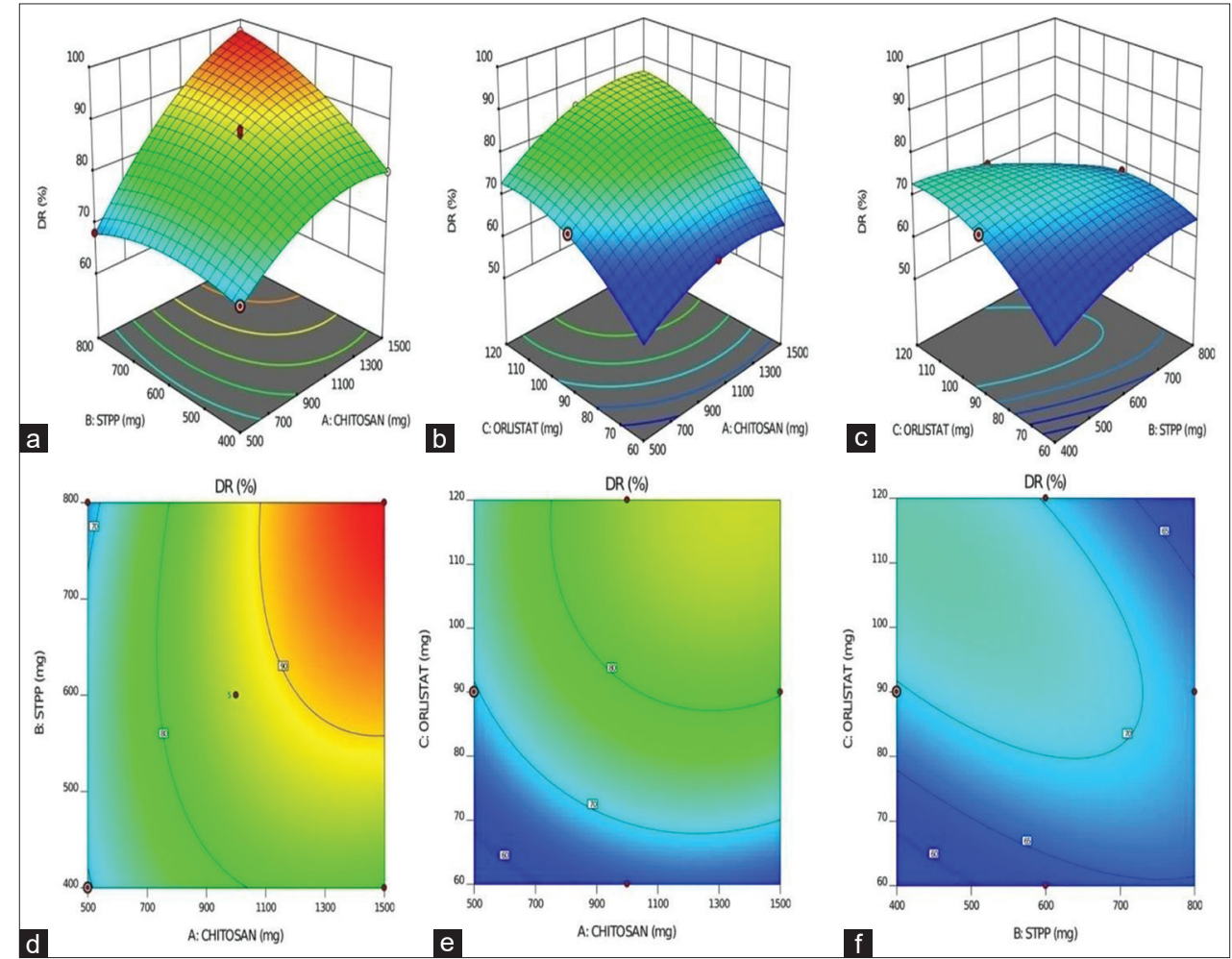

Fig. 3: Three-dimensional response surface plots showing the effect of variables on DR, (a) effect of chitosan and TPP, (b) effect of chitosan and orlistat (c) effect of TPP and orlistat. Contour plots showing effects of variables on DR (d) effect of chitosan and TPP, (e) effect of chitosan and orlistat (f) effect of TPP and orlistat

\section{FTIR study}

The spectrum of orlistat (Fig. 7) had prominent peaks at $3336.55(\mathrm{~N}-\mathrm{H}$ stretching), 2926.54 (C-H stretching), 1837.21 (C=0 stretching), 1522.91
( $\mathrm{C}=\mathrm{C}$ aromatic stretching), and 1200.04 ( $\mathrm{C}-\mathrm{N}$ bending), respectively. The FTIR spectrum of chitosan showed characteristic peak at 1515.77 (CH stretching), $1628.63 \mathrm{~cm}^{-1}$ ( $\mathrm{C}=0$ stretching of amide $\left.\mathrm{I}\right), 1700.78 \mathrm{~cm}^{-1}(\mathrm{C}=0)$, 


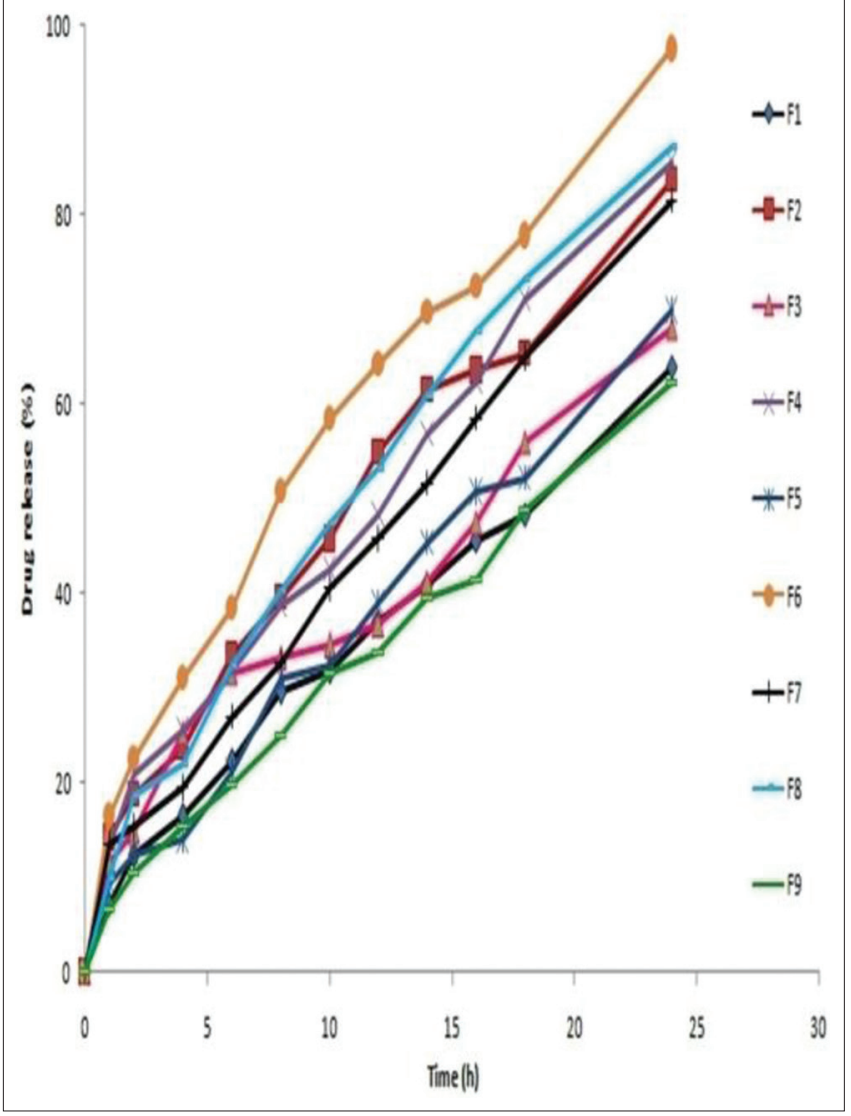

Fig. 4: Drug release profiles of CONPs F1-F9

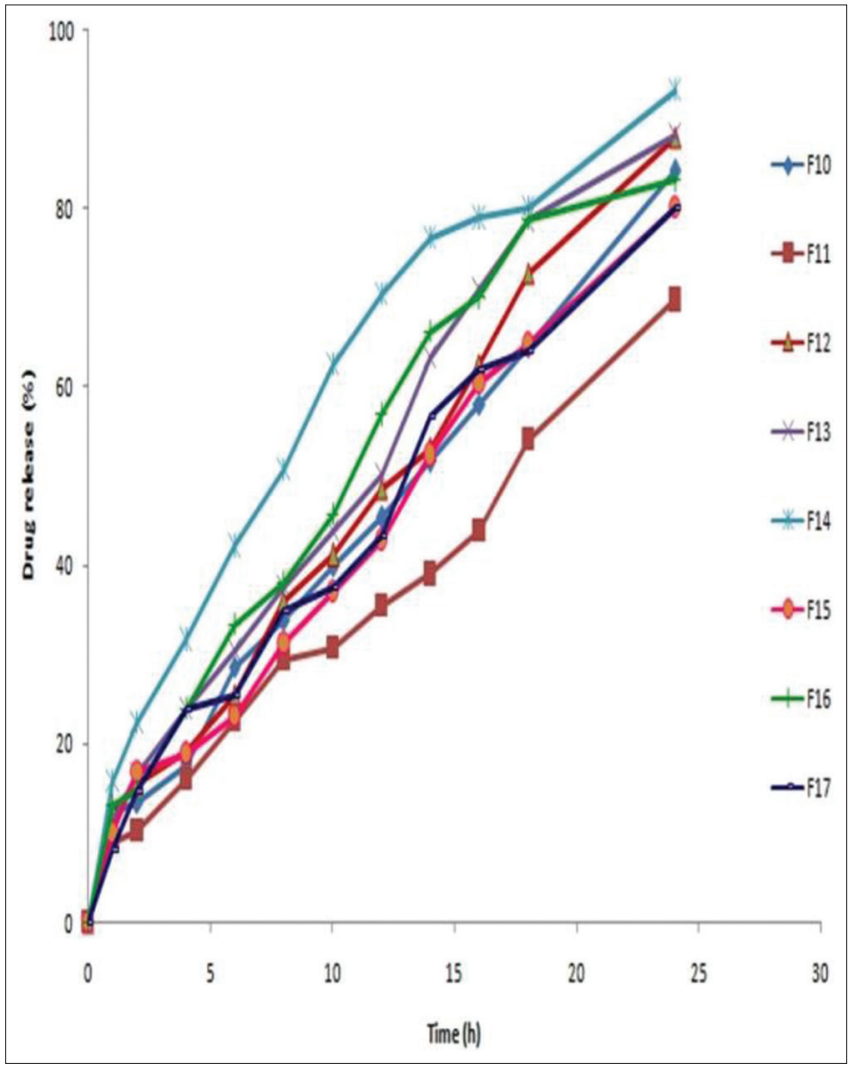

Fig. 5: Drug release profiles of CONPs of F10-F17

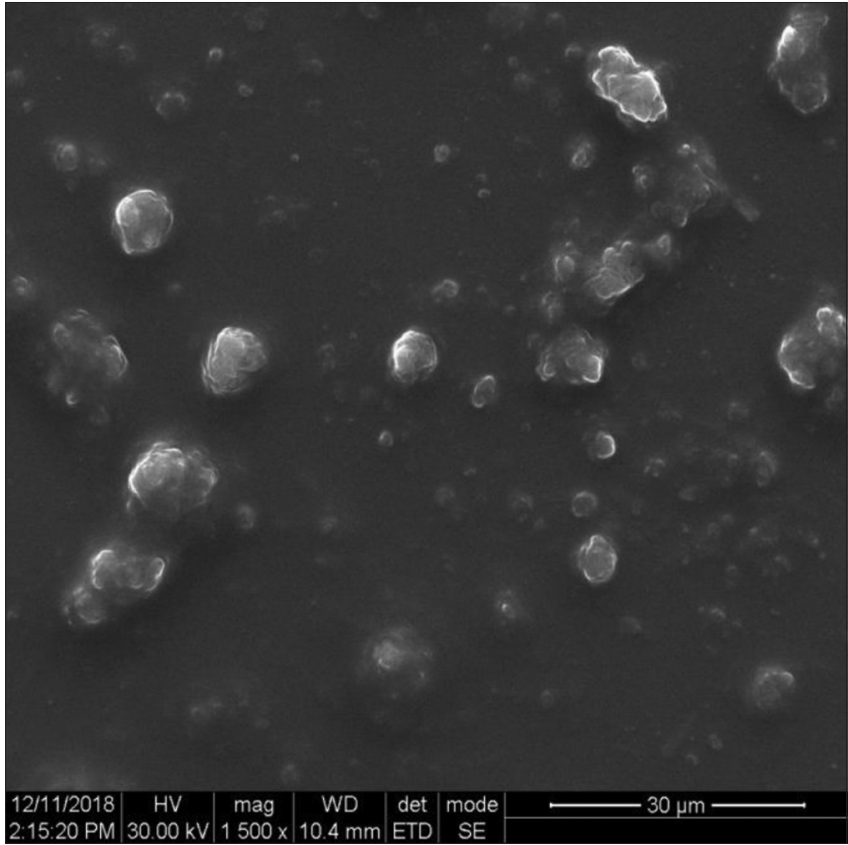

Fig. 6: Morphology of ECONP
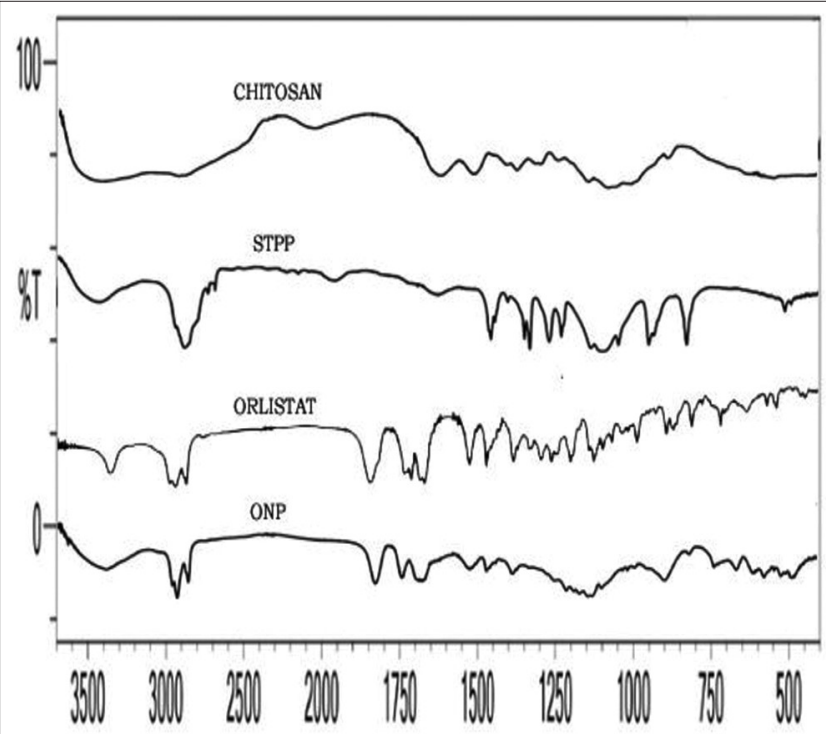

(III)

Fig. 7: FTIR spectra of Chitosan, TPP, Orlistat, and ONP

and $3421 \mathrm{~cm}^{-1}$ (combined peaks of primary $-\mathrm{NH}_{2}$ and -OH). FTIR of TPP showed a characteristic peak at $2915 \mathrm{~cm}^{-1}$ (C-H stretching). No apparent shift in the principal functional groups of orlistat was identified in the FTIR spectra which indicated the compatibility of orlistat with excipients.

\section{X-ray diffraction}

XRD studies of orlistat (Fig. 8a) showed a range of sharp crystalline peaks at different $2 \theta$ values from 10.0 to 30.0 . The developed formulation clearly exhibited the presence of crystalline phase of orlistat in nanoparticles.

\section{Differential scanning calorimetry}

DSC thermograms of chitosan, orlistat, and optimized formulation are depicted in Fig. 8b. A broad endothermic peak of orlistat was depicted at $142-175^{\circ} \mathrm{C}$ and peak was shifted to $118-145^{\circ} \mathrm{C}$ in the optimized formulation. 


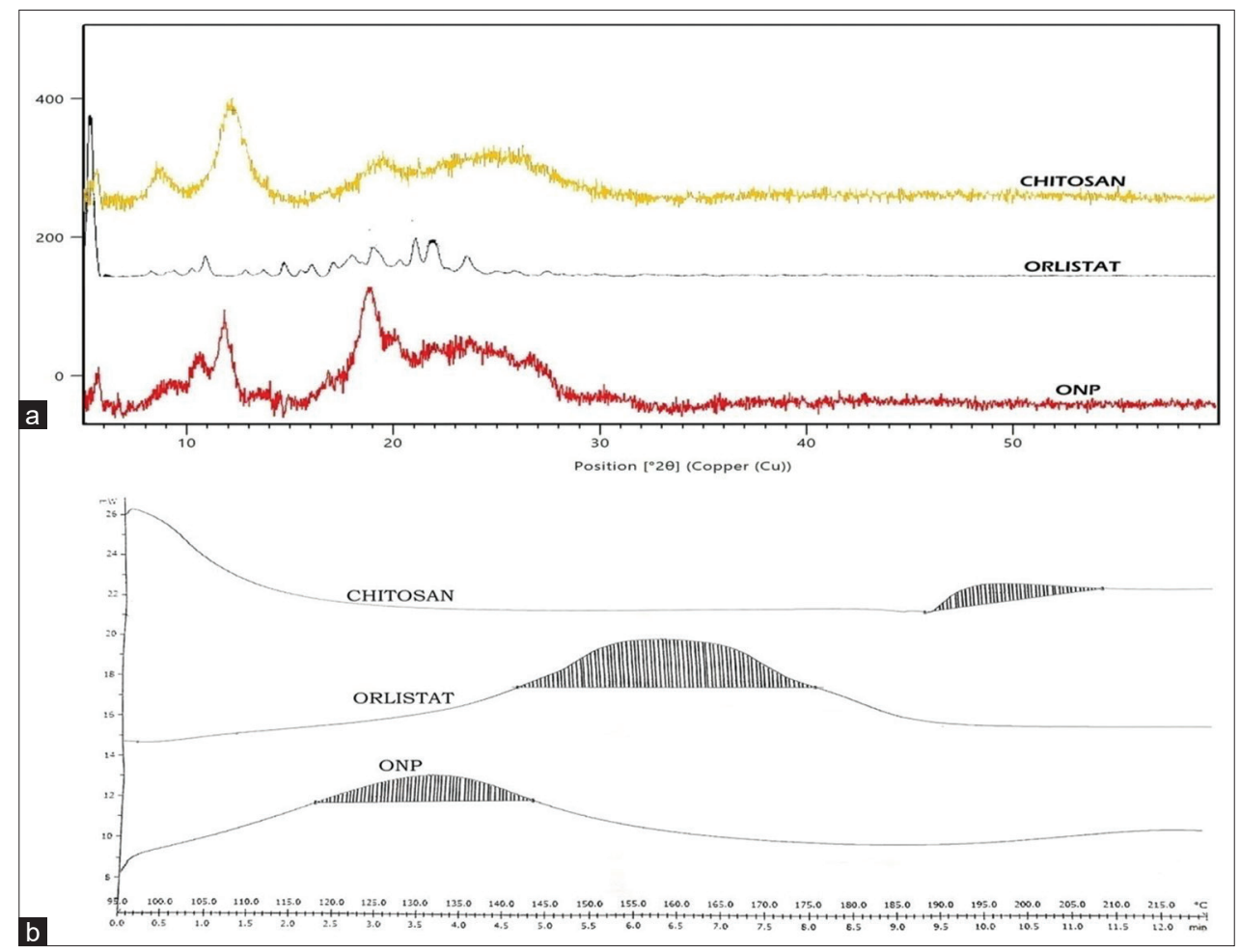

Fig. 8: (a) XRD of ECONPs and (b) DSC thermograms of ECONPs

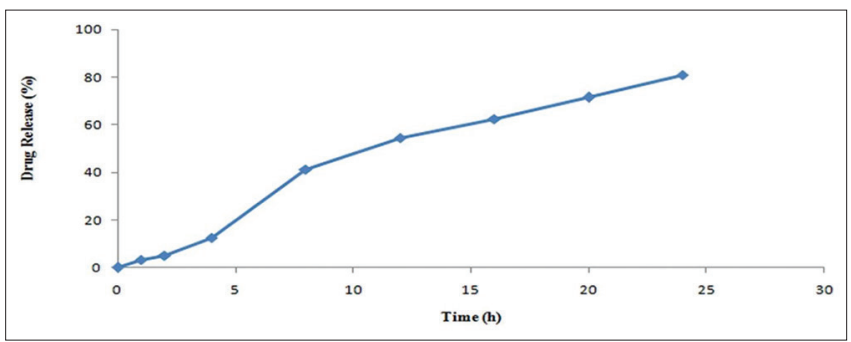

Fig. 9: Drug release of ECONPs

\section{Drug release}

Release of orlistat from ECONPs in initial $2 \mathrm{~h}\left(\mathrm{P}_{2 \mathrm{~h}}\right)$ and $24 \mathrm{~h}\left(\mathrm{P}_{24 \mathrm{~h}}\right)$ is depicted in Fig. 9. About 5.24\% of drug was released in initial $2 \mathrm{~h}\left(\mathrm{P}_{2 h^{\prime}}\right.$ $\mathrm{pH} 1.2)$ and $80.86 \%$ in subsequent $24 \mathrm{~h}\left(\mathrm{P}_{24 \mathrm{~h}} \mathrm{pH}\right.$ 6.8) effective at the desired area. The release of orlistat from the NPs followed biphasic release with First-order kinetics and Higuchi model.

\section{Stability studies}

Stability data demonstrated that there were no physical changes of ECONPs and no shift in the principal functional groups of orlistat as noticed in Fig. 10a. There was no significant difference between the samples stored at stressed conditions in terms of physicochemical integrity, drug content (84.87\%), and drug release (80.86-84.4\%) of optimized formulation (Fig. 10b). The developed ECONPs were found to be physicochemically intact over a period of three months.

\section{Lipase inhibition}

$\mathrm{IC}_{50}$ is characteristic parameter of the inhibitors; however, it also depends on the substrate, lipase, their concentration and temperature. The $\mathrm{IC}_{50}$ value of ECONPs and pure orlistat was found to be $8 \mu \mathrm{g} / \mathrm{ml}$ and $11.25 \mu \mathrm{g} / \mathrm{ml}$.

\section{In vitro cell line study (MTT assay)}

Before determining the in vivo effects of optimized formulation on biological cells, its impact on cell permeability and survival were evaluated using MTT assay. In this study, ECONPs showed a greater extent of cell viability in all three cell lines. Function of cell viability, CTC $_{50}$ values of ECONPs were 27.1, 32.21, and $26.32 \mu \mathrm{g} / \mathrm{ml}$ and that of pure orlistat were $48.25,40.17$, and $32.63 \mu \mathrm{g} / \mathrm{ml}$, respectively, for $\mathrm{MF}$ 3T3-L1, MCF-12A, and NSC-34 cells.

\section{DISCUSSION}

Orlistat-loaded chitosan nanoparticles were processed by ionic gelation method where positively charged amine groups undergone interaction with negatively charged TPP ions. Hydrophilic chitosan is an appropriate choice to fabricate CONPs with higher EE and yield proportionate to polymer concentration. In addition to chitosan concentration, amounts of cross linker (TPP), orlistat and physicochemical interactions between orlistat and chitosan showed significant role in drug EE and DR as ionic gelation had better encapsulation of hydrophobic orlistat. Quantum of each ingredient was selected by BBD to optimize the formulation of CONP. Overall impact of independent variables on the responses was elucidated through probability plots and residual plots. However, predicted and experimental responses lie nearer to and on straight line explained that derived model envisaged linear relationship between formulation variables and responses. Data were randomly dispersed within limits of \pm 3 to confirm the BBD model was adequately fit for the experimental design of CONP as shown in Fig. 1. As response surface graphs and contour plots (Fig. 2 and 3) demonstrated that the effect of variables on responses, increase in chitosan concentration (to a certain range) resulted in linear increase in $\mathrm{EE}$, and further increase lead to decreased EE. However, increased dynamic viscosity of the polymeric (CS) solution at higher concentration limited the entry of orlistat in hydrophilic polymeric network of chitosan. Similarly, increase in concentration of TPP resulted in initial increase in EE with subsequent reduction (above $600 \mathrm{mg}$ ). Nevertheless amount of orlistat had a direct and positive effect on EE. Same was signified by curvilinear contour plots with strong interactions between variables. On the other hand, an increase in chitosan concentration resulted with increased drug release due to high degree of swelling of chitosan matrix and resulted more dissolution of orlistat. Attribution was fortified with reduced intensity of characteristic peaks of orlistat which was due to dilution and partial solid state interaction of orlistat as evident 


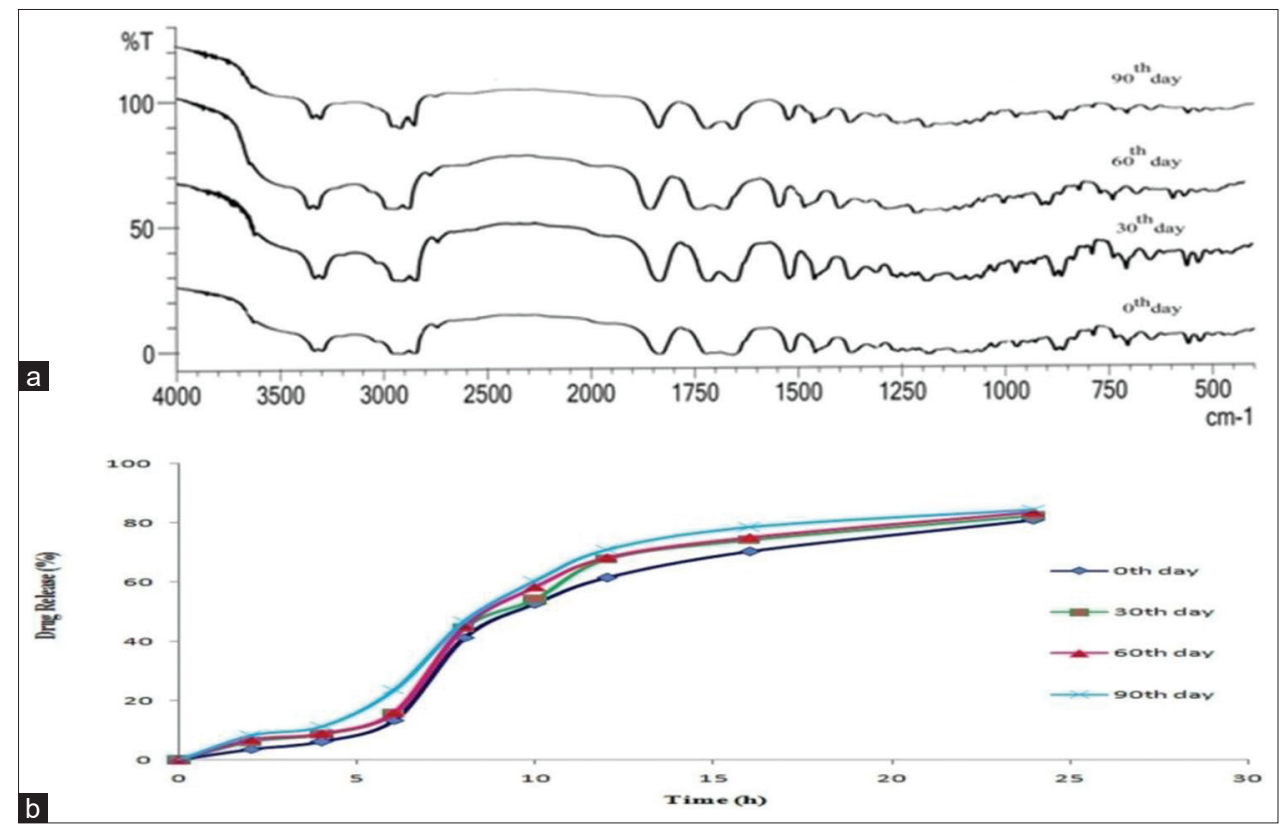

Fig. 10: (a) FTIR spectra of ECONPs from stability study, (b) drug release profiles of ECONPs (stability study)

with Fig. 7. Similarly increased orlistat concentration caused a linear increase in DR due to more drug availability within polymer matrix. Conversely, higher degree of TPP retarded the release of orlistat from chitosan network, but a slight increase (72.19\%) followed by decrease $(68.76 \%)$ in DR was resulted as displayed as curvilinear contour plots with moderate interaction between the variables. However, at optimum concentrations of drug, carrier and TPP, high EE, and DR were deduced. Beyond optimized amounts, these three ingredients had no profound effect on both responses. Software generated model graphs (predicted vs. actual and residual vs. predicted) for all responses were produced without outliers and indicated the adequacy of BBD. As BBD was a well suitable experimental design in predicting the responses of CONPs, optimal concentrations of integrants and so as to produce an optimized CONP with $85.8 \mathrm{~nm}$ size and $+5.7 \mathrm{mV}$ zeta potential. CONPs released the orlistat with an initial burst release due to weak physical adsorption on huge surface area of nanoparticles, followed by sustained release. Consequently, Eudragit L100 treated CONPs released orlistat at duodenal specific $\mathrm{pH}$ in three phases, namely, initial lag phase $\left(\mathrm{pH} 1.2, \mathrm{P}_{2 \mathrm{~h}}\right)$ as attributed as the impermeability of acidic medium through the coated layer of Eudragit L100, followed by burst release due to complete dissolution of Eudragit coat exposing surface adsorbed orlistat, later sustained release phase $\left(\mathrm{pH} 6.8, \mathrm{P}_{24 \mathrm{~h}}\right)$. Entangled orlistat in chitosan polymeric network was released out in sustained mode by following the first-order release with Higuchi kinetic model up to $24 \mathrm{~h}$. As demonstrated, $\mathrm{pH}$ dependent solubility, gastroretentive potentials of Eudragit L100 and complied the specifications of USP (2013) for enteric-coated ECNOP, with $\mathrm{P}_{2 \mathrm{~h}}$ of less than $10 \%$. Further, the sustained drug release profiles for $24 \mathrm{~h}$, at $\mathrm{pH} 6.8$ attributed due to the protonation or deprotonation of Eudragit L100 at various pH conditions. As per earlier studies, the carboxylic groups of Eudragit L100 undergone protonation at $\mathrm{pH}$ values below the pKa of methacrylic acid of 4.23. Under the simulated acidic milieu of the stomach ( $\mathrm{pH} 1.2)$, the enteric surface-coated nanoparticles were protonated thereby decrease the surface charges and electrostatic repulsions. Thus, established Van der Waals forces aggregated the ECONPs and conversely at simulated intestinal milieu (pH 6.8) carboxylic groups were deprotonated [28] and thus biphasic release of orlistat was manifested. As drug release at pH 6.8 showed comparable trends with targeted release, ECNOPs could facilitate the reduction in dosing frequency for patient compliance. Addition to above context, enlarged particle size to $534.6 \mathrm{~nm}$ (ECONPs) could facilitate duodenal targeting and increased residence time by anchoring the particles at duodenum instead of being rapid absorption.
Although the polymeric NPs have undergone ionic gelation with counterions (TPP), they still possessed positive charge due to amino groups of hydrophilic chitosan/Eudragit. Extended positive charge ensued the stability of CS-NPs by virtue of optimum zeta potential $(+5.7 \mathrm{mV})$. These positively charged domains of CS had electrostatically interacted with sialic groups of mucin and potentiated mucoadhesion of NPs and further inhibit duodenal lipase activity. However, the low electrokinetic potentials resulted with weak repulsive forces between particles which could offer more bioabsorption. With improved solubility of orlistat on dispersion of formulation in media bestowed lipase inhibition with orlistat and lag time for ECONPS was manifested due to coatings of Eudragit. Subsequently, enteric polymer treated orlistat nanoparticles showcased viability against selected cell lines without affecting their functions. As ECNOPs were better compatible and permeable to selected cell-lines, reduction of MTT (yellow) by mitochondrial succinate dehydrogenase to an insoluble formazan product (dark purple)in metabolically active cells was established without any effect on viability of cells. As data not shown, orlistat alone has also possessed similar mode of compatibility and permeability with cells. These outcomes fortified the duodenal targeting of orlistat with extended residence of ECNOPs, superior lipase inhibition, without altering the viability of duodenal cells, proper mucoadhesion, and bioabsorption.

\section{CONCLUSION}

Orlistat-loaded CS-NPs were successfully processed by ionic gelation technique. BBD was proved to be efficient, logistic approach in designing and optimizing the CONPs. Further surface engineering of optimized formulation (ECONPs) with enteric Eudragit polymer facilitated the release of orlistat at targeted $\mathrm{pH}$ over $24 \mathrm{~h}$ by following first order release with Higuchi kinetic model. Spherical ECONPs produced were stable, optimum sized with favorable positive surface charge. Sustained release of drug at desired $\mathrm{pH}$, enhanced in vitro lipase inhibition and better cell viability of ECONPs become promising delivery system for duodenal targeting of orlistat. Further in vivo and preclinical studies are essential to prove the concept of duodenal targeting of ECONPs for antiobesity potentials of ECONPs.

\section{ACKNOWLEDGMENTS}

The authors are grateful to M/s Aurobindo Pharma Ltd, Hyderabad, India, for gratis of orlistat and the management of Sri Padmavathi 
School of Pharmacy, Tirupati, India, for rendering generous support to carry out the research work.

\section{AUTHORS CONTRIBUTIONS}

All authors contributed to the conception, design, interpretation, and compilation of results, and execution of the study. The corresponding author drafted the manuscript, and incorporated the suggestions from co-authors.

\section{CONFLICT OF INTEREST}

The authors declare that there are no conflicts of interest regarding the publication of this manuscript.

\section{FUNDING}

All authors had declared that they did not receive any funding from government or private or any other organizations.

\section{REFERENCES}

1. Yumuk V, Tsigos C, Fried M, Schindler K, Busetto L, Obesity Management Task Force of the European Association for the Study of Obesity. European guidelines for obesity management in adults. Obes Facts 2015;8:402-24

2. Blackburn GL, Wollner S, Heymsfield SB. Lifestyle interventions for the treatment of class III obesity: A primary target for nutrition medicine in the obesity epidemic. Am J Clin Nutr 2010;91:289-92.

3. Finer N. Medical consequences of obesity. Medicine 2015;43:88-93.

4. Sabrin RI, Gamal AM, Zainy MB. Natural antihyperlipidemic agents: Current status and future perspectives. Phytopharmacology 2013;4:492531.

5. Henness S, Perry CM. Orlistat: A review of its use in the management of obesity. Drugs 2006;66:1625-56.

6. Mittendorfer B, Ostlund RE, Patterson BW, Klein S. Orlistat inhibits dietary cholesterol absorption. Obes Res 2001;9:599-604.

7. Hill TK, Davis AL, Wheeler FB, Kelkar SS, Freund EC. Development of a self-assembled nanoparticle formulation of orlistat, Nano-ORL, with increased cytotoxicity against human tumor cell lines. Mol Pharm 2016;13:720-8.

8. Sangwai M, Sardar S, Vavia P. Nanoemulsified orlistat-embedded multi-unit pellet system (MUPS) with improved dissolution and pancreatic lipase inhibition. Pharm Dev Technol 2014;19:31-41.

9. Dolenc A, Govedarica B, Dreu R, Kocbek P, Srcic S, Kristl J. Nanosized particles of orlistat with enhanced in vitro dissolution rate and lipase inhibition. Int J Pharm 2010;396:149-55.

10. Rukmangathen R, Yallamalli IM, Yalavarthi PR. Biopharmaceutical potential of selegiline loaded chitosan nanoparticles in the management of Parkinson's disease. Curr Drug Discov Technol 2019;16:417-25.

11. Jabr-Milane L, Van Vlerken L, Devalapally H, Shenoy D, Komareddy S. Multi-functional nanocarriers for targeted delivery of drugs and genes. J Control Release 2008;130:121-8.

12. Naghibi Beidokhti HR, Ghaffarzadegan R, Mirzakhanlouei S, Ghazizadeh L, Dorkoosh FA. Preparation, characterization, and optimization of folic acid-chitosan-methotrexate core-shell nanoparticles by Box-Behnken design for tumor-targeted drug delivery. AAPS PharmSciTech 2017;18:115-29.

13. Nguyen N, John JB. New 3-level response surface designs constructed from incomplete block designs. J Stat Plan Inf 2008;138:294-305.

14. Li P, Yang Z, Wang Y, Peng Z, Li S, Kong L, et al. Microencapsulation of coupled folate and chitosan nanoparticles for targeted delivery of combination drugs to colon. J Microencapsul 2015;32:40-5.
15. Rawal T, Mishra N, Jha A, Bhatt A, Tyagi RK, Panchal S, et al. Chitosan nanoparticles of gamma-oryzanol: Formulation, optimization, and in vivo evaluation of anti-hyperlipidemic activity. AAPS PharmSciTech 2018;19:1894-907.

16. Gajra B, Patel RR, Dalwadi C. Formulation, optimization and characterization of cationic polymeric nanoparticles of mast cell stabilizing agent using the Box-Behnken experimental design. Drug Dev Ind Pharm 2016;42:747-57.

17. Honary S, Ebrahimi P, Hadianamrei R. Optimization of particle size and encapsulation efficiency of vancomycin nanoparticles by response surface methodology. Pharm Dev Technol 2014;19:987-98.

18. Pandit J, Sultana Y, Aqil M. Chitosan-coated PLGA nanoparticles of bevacizumab as novel drug delivery to target retina: Optimization, characterization, and in vitro toxicity evaluation. Artif Cells Nanomed Biotechnol 2017;45:1397-407.

19. Katamreddy JD, Yalavarthi PR, Rao DS, Teja SS, Battu S. In vitro characterization of statistically optimized quetiapine-loaded self-nanoemulsified systems with quality by design. Int J Pharm Invest 2018;8:14-3

20. Abul Kalam M, Sultana Y, Ali A, Aqil M, Mishra AK, Aljuffali IA, et al. Part I: Development and optimization of solid-lipid nanoparticles using Box-Behnken statistical design for ocular delivery of gatifloxacin. J Biomed Mater Res A 2013;101:1813-27.

21. Rukmangathen R, Yallamalli IM, Yalavarthi PR. Formulation and biopharmaceutical evaluation of risperidone-loaded chitosan nanoparticles for intranasal delivery. Drug Dev Ind Pharm 2019;45:1342-50.

22. Ahmed IS, El-Hosary R, Shalaby S, Abd-Rabo MM, Elkhateeb DG, Nour S. PD-PK evaluation of freeze-dried atorvastatin calcium-loaded poly- $\varepsilon$-caprolactone nanoparticles. Int J Pharm 2016;504:70-9.

23. Wang Y, Li P, Zheng P. Microencapsulation of nanoparticles with enhanced drug loading for $\mathrm{pH}$-sensitive oral drug delivery for the treatment of colon cancer. J Appl Polym Sci 2013;129:714-20.

24. Woitiski CB, Neufeld RJ, Ribeiro AJ, Veiga F. Colloidal carrier integrating biomaterials for oral insulin delivery: Influence of component formulation on physicochemical and biological parameters. Acta Biomater 2009;5:2475-84.

25. Shah HA, Patel RP. Statistical modeling of zaltoprofen loaded biopolymeric nanoparticles: Characterization and anti-inflammatory activity of nanoparticles loaded gel. Int J Pharm Invest 2015;5:20-7.

26. Rahman Z, Zidan AS, Habib MJ, Khan MA. Understanding the quality of protein loaded PLGA nanoparticles variability by Plackett-Burman design. Int J Pharm 2010;389:186-94

27. Chaves LL, Costa Lima SA, Vieira AC, Barreiros L, Segundo MA, Ferreira D, et al. $\mathrm{pH}$-sensitive nanoparticles for improved oral delivery of dapsone: Risk assessment, design, optimization and characterization. Nanomedicine (Lond) 2017;12:1975-90.

28. Tayel AS, Mohamed A. Duodenum-triggered delivery of pravastatin sodium: II. Design, appraisal and pharmacokinetic assessments of enteric surface-decorated nanocubosomal dispersions. Drug Deliv 2016;23:3266-78.

29. Shailender J, Ravi PR, Reddy Sirukuri M, Dalvi A, Keerthi Priya O. Chitosan nanoparticles for the oral delivery of tenofovir disoproxil fumarate: Formulation optimization, characterization and ex vivo and in vivo evaluation for uptake mechanism in rats. Drug Dev Ind Pharm 2018;44:1109-19.

30. Rossato FA, Zecchin KG, La Guardia PG, Ortega RM, Alberici LC, Costa RA, et al. Fatty acid synthase inhibitors induce apoptosis in nontumorigenic melan-a cells associated with inhibition of mitochondrial respiration. PLoS One 2014;9:e101060.

31. Sternby B, Hartmann D, Borgström B, Nilsson A. Degree of in vivo inhibition of human gastric and pancreatic lipases by Orlistat (Tetrahydrolipstatin, THL) in the stomach and small intestine. Clin Nutr 2002;21:395-402. 